\title{
WELKE VERANTWOORDELIJKHEID DRAAGT DE ACCOUNTANT VOOR TUSSENTIJDSE BERICHTEN?
}

\author{
door Prof. A. B. Frielink
}

\section{Inleiding}

In het jaarverslag 1964/65 van de C.A.B.1) heeft deze zich uitgesproken omtrent het reeds in 1961 aan de orde gestelde vraagstuk van de verantwoordelijkheid van de accountant voor tussentijdse cijfers.

Op de jaarlijkse algemene ledenvergadering van het N.I.v.A. op 18 december 1965 is hierover van gedachten gewisseld, zonder dat het mogelijk was tot een systematische analyse te komen. Toch is, naar mij voorkomt, daaraan behoefte. Het onderstaande is een poging tot systematische analyse en als zodanig een bijdrage tot de discussie over het onderwerp. Aan het slot zal getracht worden enkele normatieve conclusies te trekken; dit kan worden gezien als een bijdrage aan de meningsvorming.

\section{Probleemstelling}

Aangezien het verschijnsel van ,tussentijdse berichtgeving” zich in tal van vormen en omstandigheden voordoet, is het noodzakelijk het onderwerp af te bakenen en in te delen.

Ten aanzien van de afbakening wil ik mij aansluiten bij de C.A.B.: Het onderwerp betreft de tussentijdse berichten omtrent de gang van zaken bij een huishouding waar een openbaar accountant fungeert, die niet als zodanig zijn voorzien van een certificaat van juistheid, afgegeven door die accountant.

Ten aanzien van de indeling wil ik tot op zekere hoogte de C.A.B. volgen:

a. Zelfstandige in het publieke verkeer gebrachte periodieke berichten, voorzien van een tussentijdse resultatenrekening en balans of alleen van een tussentijdse resultatenrekening. Kenmerkend voorbeeld: kwartaalbericht.

b. In het publieke verkeer gebrachte (al dan niet periodieke) tussentijdse berichten, voorzien van een tussentijdse resultatenrekening (evt. en balans), die deel uitmaken van een stel van bescheiden waarin de naam van de fungerende accountant voorkomt. Het kenmerkende voorbeeld van deze categorie is het emissieprospectus.

c. In het publieke verkeer gebrachte, niet periodieke, tussentijdse berichten, voorzien van een tussentijdse resultatenrekening (evt. en balans), die geen deel uitmaken van een stel van bescheiden als onder b. bedoeld. Kenmerkend voorbeeld: fusieberichten.

d. In het publieke verkeer gebrachte berichten, niet voorzien van een resultatenrekening of een balans, waarin gegevens omtrent de huishouding worden vermeld die normaliter uit de jaarrekening zijn af te leiden. Als kenmerkend voorbeeld kan worden genoemd de mededeling over omzet- en resultatenontwikkeling in het lopende jaar, tijdens de jaarlijkse algemene vergadering van aandeelhouders.

e. Niet in het publieke verkeer gebrachte mededelingen omtrent de ontwikkeling

1) Commissie van advies inzake beroepsaangelegenheden van het Nederlands Instituut van Accountants. De Accountant 72 (1965/66), nr. 2 p. 96 e.v. 
van resultaten en vermogen gedurende een nog niet afgesloten periode. Het hier te noemen kenmerkende voorbeeld is het overleg met de bankier over een aangevraagde kredietfaciliteit.

Voorzover nodig wordt nog gepreciseerd dat onder „publiek verkeer" in het vorenstaande wordt verstaan: ,de kring van personen buiten die van de directbelanghebbenden". Dit wil zeggen dat bijvoorbeeld berichten uitgaande aan de met name bekende aandeelhouders van een besloten N.V., zonder dat tevens het bericht aan de financiële pers wordt verstrekt, niet geacht worden in het publieke verkeer te zijn gebracht. In sommige gevallen zal het van de feitelijke omstandigheden afhangen of men al dan niet tot een brengen in het publieke verkeer concludeert. Men denke bijvoorbeeld aan berichten (individueel geadresseerd, onder gesloten couvert en misschien zelfs voorzien van het opschrift "Vertrouwelijk”) aan de duizend of meer leden van een grote Coöperatieve Vereniging.

\section{Afleiding van de verantwoordelijkbeid van de accountant}

Indien we willen trachten een uitspraak te doen omtrent de verantwoordelijkheid van de accountant voor bepaalde mededelingen van een gecontroleerde, is het doelmatig de algemene analyse van Limperg als uitgangspunt te nemen. Ik moge de lezer in herinnering roepen dat voor Limperg de onderscheiding van de accountantsfunctic in

- controlerend (en adviserend) orgaan van de bedrijfsleiding;

- controlerend (en adviserend) orgaan van het maatschappelijk verkeer ${ }^{2}$ );

de belangrijkste is ${ }^{3}$ ). In de meerderheid der gevallen worden beide deelfuncties ongedeeld vervuld door de openbare accountant. De algemene functie (en daarmede de specifieke functies waaruit die is opgebouwd) wortelt in het vertrouwen dat in het maatschappelijk verkeer gesteld wordt in de doeltreffendheid der controle en in bet oordeel van de accountant ${ }^{4}$ ).

Er zijn twee mogelijkheden indien het gestelde vertrouwen en de wijze van vervulling der functie elkaar niet dekken: er kan zijn een overdreven vertrouwen of er kan zijn een tekortkoming in de vervulling van de functie ${ }^{5}$ ). Een te laag gestelde verwachting levert evenzeer bezwaren op als een te hoog gestelde verwachting. Er is een norm van vertrouwen dat de verstandige leek in de functie van de accountant stelt, welke norm uit de behoeften van het maatschappelijk verkeer is gegroeid (en verder groeit).

De accountant draagt de verantwoordelijkheid dat het vertrouwen dat hij met zijn verklaring omtrent een rekening wekt, gerechtvaardigd is op grond van de controlewerkzaamheden die door hem zijn verricht.

De beroepsreglementen geven een ruime definitie voor het begrip „verklaring": „elke mededeling, hetzij schriftelijk of mondeling gedaan, waarin een oordeel wordt kenbaar gemaakt of waaruit een oordeel te kennen is".

Het is duidelijk, dat zonder „,verklaring” geen vertrouwen kan worden gewekt

2) Men verwarre niet het in paragraaf 2 genoemde "publieke verkecr" met het Limpergiaanse "maatschappelijk verkeer". Dit laatste staat tegenover de bedrijfsleiding; het cerste tegenover de direct-belanghebbenden.

3) Vergelijk in de bundel MAB 1924-1960, deel 2, p. 140/141.

4) Ibid. p. 149 .

5) Ibid. p. 150.

$\mathrm{m} \mathrm{a} \mathrm{b}$ blz. 231 
en derhalve geen verantwoordelijkheid bestaat. Men hoede zich er echter voor, hieruit af te leiden dat pas de formele daad van het ,afgeven van een accountantsverklaring" vertrouwen zou opwekken. Hier wreekt zich de terminologische afwijking tussen het spraakgebruik en de - veel principiëlere - beroepsreglementen. Wij zijn gewoon een paragraaf in onze rapporten aan te duiden als „Verklaring”, daarmede miskennende dat vele andere mededelingen in het rapport en ook vele mededelingen gedurende de controle aan de leiding (soms ook aan anderen) gedaan reglementair cvenzeer ,,verklaringen” zijn.

In het algemeen kan men stellen dat het in continuïteit blijven fungeren als accountant van een huishouding reeds als een ,verklaring" moet worden opgevat: een oneigenlijke mededeling, inhoudende dat zich naar het oordeel van de accountant geen omstandigheden hebben voorgedaan die het verder fungeren onaanvaardbaar maken.

Hier moet bij worden aangetekend dat een dergelijke oneigenlijke ,verklaring” uiteraard alleen kan werken ten aanzien van degenen die weten dat de accountant blijft fungeren. Ieder die niet uit hoofde van zijn functie weet of de accountant al dan niet nog fungeert, kan geen vertrouwen afleiden uit het feit dát de accountant nog fungeert. De accountant kan te zijnen opzichte ook geen verantwoordelijkheid dragen.

\section{Toepassing op de verschillende gevallen van tussentijdse berichtgeving}

\section{Ad a. Kwartaalberichten e.d.}

Tussentijdse resultatenoverzichten en vermogensopstellingen die onjuistheden ${ }^{6}$ ) vertonen zijn een verhindering voor de accountant te blijven fungeren. Deze verantwoordelijkheid van de accountant wordt afgeleid uit de gegroeide norm van vertrouwen: De opdrachtgever kan terecht verwachten dat de accountant belast met de algemene controle, mede toezicht houdt op de effectiviteit van de administratieve organisatic en het daarin vervatte stelsel van interne controle, zodat de accountant hem zal waarschuwen indien zich gebreken voordoen die geleid hebben of kunnen leiden tot onjuistheden in tussentijdse overzichten (evenals trouwens op tal van andere punten die hier buiten discussie blijven). Wellicht is dit in het nog niet zo verre verleden anders geweest; er lijkt geen twijfel aan dat deze verwachting van de opdrachtgever thans behoort tot de gegroeide norm.

Tegenover de opdrachtgever (geconcretiseerd: bcstuur en toezichtorgaan) draagt de accountant dientengevolge de verantwoordelijkheid voor de juistheid van de tussentijdse overzichten. Wil men dit afzwakken tot een ,verantwoordelijkheid in hoofdzaken"7) dan is mij dat wel. Ik zie geen principieel verschil met de verantwoordelijkheid van de accountant voor de effectiviteit van de administratieve organisatie in het algemeen.

Deze verantwoordelijkheid kan echter niet zonder meer impliceren een verantwoordelijkheid tegenover anderen dan de opdrachtgever (geconcretiseerd: aandeelhouders, potentiële aandeelhouders, crediteuren, personeel). Zii immers kunnen uit hoofde van hun functie niet weten of de accountant blijft fungeren;

6) Waar van onjuistheden wordt gesproken, wordt uitsluitend gedoeld op onjuistheden dic van belang zijn voor het uit een rekening of bericht af te leiden oordeel.

7) De Accountant 72 (1965/66), nr. 2 p. 99. 
zij beschikken niet over enig middel (expliciet of impliciet) om van het oordeel van de accountant kennis te nemen.

Het is uiteraard voor deze sector van het maatschappelijk verkeer verleidelijk om uit het feit dat een bepaalde openbare accountant reeds gedurende een reeks van jaren een goedkeurende verklaring met betrekking tot de jaarrekening in het jaarverslag laat afdrukken, af te leiden dat die accountant nog wel zal fungeren en dus de verantwoordelijkheid voor het tussentijdse bericht draagt. Het is echter de taak van de accountantsstand duidelijk te maken dat het gefungeerd hebben in het verleden generlei garantie inhoudt voor het blijven fungeren, en dat er thans voor de accountant ook geen aanvaardbaar middel bestaat om publiekelijk van eventuele bezwaren tegen het tussentijdse overzicht of van zijn defungeren kennis te geven.

Er bestaat een gevaar voor bevordering van dit verleidelijk overdreven vertrouwen indien ondiscriminerend wordt gesteld dat de, accountant zich niet aan iedere verantwoordelijkheid voor de inhoud van deze berichten kan onttrekken" 8 ).

Men kan zich afvragen of het gewenst zou zijn wegen te openen om van be$z$ waren tegen de inhoud van tussentijdse overzichten, resp. van het defungeren publiekelijk mededeling te doen. Hier moet onderscheid worden gemaakt tussen het - weinig frequente - geval dat de accountant door de aandeelhoudersvergadering is benoemd, en het usantiële geval dat benoeming door commissarissen is geschied. In beide gevallen vloeit uit de accountantsverantwoordelijkheid voort dat hij zijn opdrachtgever op de hoogte stelt van omstandigheden die zijn functie kunnen verstoren. Ten aanzien van de met name bekende commissarissen is dit geen bijzonder probleem; ten aanzien van de anonieme aandeelhouders van een open N.V. zou slechts een ,bericht" op dezelfde wijze verspreid als het tussentijdse bericht van de leiding der huishouding het gewenste effect hebben. Vooralsnog lijkt mij een dergelijk in het openbaar treden van de accountant ongewenst; zolang de benoeming door de aandeelhoudersvergadering slechts bij hoge uitzondering voorkomt, is dit probleem weinig actueel.

De ongewenstheid van het in het openbaar treden geldt - naar mijn subjectieve oordeel - evenzeer ten aanzien van de andere sectoren van het maatschappelijk verkeer (potentiële aandeelhouders, crediteuren, personeel).

Het zou wellicht tot een ander oordeel leiden, indien wettelijk zou zijn voorgeschreven dat de naam van de accountant die de (verplichte) algemene controle uitoefent in het Handelsregister moet worden ingeschreven. Daarbij zou dan mogelijkerwijze plaats zijn voor een voorschrift dat de accountant bezwaren tegen tussentijdse berichten (die dan ook bij de Kamer van Koophandel en Fabrieken moeten worden gedeponeerd) schriftelijk ter kennis van de Kamer brengt, die ze bij het bericht ter openbare raadpleging legt.

Voorlopig is het nog niet zover en kan slechts geconcludeerd worden:

- dat de accountant belast met de algemene controle tegenover de opdrachtgever verantwoordelijkheid draagt voor de tussentijdse berichten;

- dat anderen dan de opdrachtgever hieraan niet het vertrouwen mogen ontlenen dat de tussentijdse berichten naar het oordeel van de accountant juist zijn;

- dat de accountant derhalve tegenover anderen dan de opdrachtgever geen verantwoordelijkheid voor de juistheid van tussentijdse overzichten draagt,

8) De Accountant 72 (1965/66), nr. 2 p. 99. 
omdat hem de mogelijkheid ontbreekt van bezwaren te doen blijken, resp. van zijn aftreden mededeling te doen aan die anderen.

Het is ter vermijding van misverstand wellicht dienstig er op te wijzen dat vorenstaande conclusies slechts betrokken zijn op de huidige situatie. Ik meen dat de betekenis van de tussentijdse periodieke berichtgeving voor het maatschappelijk verkeer zodanig groeiende is dat er binnen afzienbare tijd een maatschappelijke behoefte zal bestaan aan een onafhankelijk oordeel omtrent de juistheid daarvan. De accountant zal geroepen zijn dit oordeel te geven. Dit betekent dat het voldoen aan deze maatschappelijke behoefte - zo die inderdaad wordt onderkend - door de accountantsstand dient te worden bevorderd. Maar dan op adequate wijze; dat wil zeggen niet slechts met behulp van een dynamische controletechniek, maar ook en in het bijzonder, door expliciet (door middel van een certificaat) dat onafhankelijke accountantsoordeel tot uitdrukking te brengen. Als de accountant van oordeel is dat het tussentijdse bericht een juist beeld geeft, dat hij dat ook zegge, zodat iedere lezer van het bericht daarvan op de hoogte is. Enige terughouding terzake omdat de tolerantie in het tussentijds overzicht veelal groter is dan in de jaarrekening is slechts op zijn plaats indien het maatschappelijk verkeer dit verschil in tolerantie niet zou onderkennen. Ook de argumenten van de korte beschikbare tijd en de hogere kosten ${ }^{8}$ ) tegen certificering kunnen weinig doorslaggevend zijn, indien men - terecht - reeds van oordeel is dat de accountant ermede bemoeienis moet hebben en , de stukken tijdig voor het ter perse gaan ter beschikking moet krijgen".

\section{A d b. Emissieprospectussen e.d.}

Tegenover de opdrachtgever geldt hier uiteraard precies hetzelfde als hierboven ten aanzien van de kwartaalberichten is opgemerkt.

Tegenover anderen dan de opdrachtgever (het publieke verkeer) bestaat nu echter een principieel andere situatie. Het gepubliceerde stuk (emissieprospectus o.d.) bevat nu immers de naam van de accountant. Ieder die van het stuk kennisneemt weet dat de accountant nog fungeert (c.q. dat thans een andere accountant fungeert); hij kan terecht het vertrouwen hebben dat de accountant zich ook een oordeel heeft gevormd over de juistheid van het tussentijdse overzicht.

Ook rechtstreeks uit de beroepsreglementen (art. 14, lid 1, R.v.A., handelende over het „stel van bescheiden") valt de verantwoordelijkheid van de accountant in dit geval af te leiden. Het tussentijdse overzicht in het emissieprospectus vertoont immers cen nauwe samenhang met de jaarrekeningen over verstreken boekjaren. Ook indien men deze reglementsbepaling hier niet van toepassing acht, blijft de verantwoordelijkheid echter ten volle bestaan.

Het komt mij dan ook voor dat de C.A.B. hier ten onrechte stelt dat de verantwoordelijkheid ,naar analogie van het onder a gestelde" moet worden gezien. ${ }^{9}$ )

Ad c. Fusieberichten e.d.

Ten principale geldt hetzelfde als ten aanzien van de kwartaalberichten (ad a.): verantwoordelijkheid tegenover degenen die weten dat de accountant nog fungeert. De facto kan deze kring in dit geval groter zijn dan de opdrachtgever in enge zin, omdat bijvoorbeeld ook de fusie-partners op de hoogte kunnen zijn.

9) De Accountant $72(1965 / 66)$, nr. 2 p. 100. 
Praktisch kan bovendien een verschil bestaan omdat niet met een vaste periodiciteit tussentijdse berichten worden gepubliceerd. Dientengevolge zal de organisatie voor het samenstellen van te publiceren tussentijdse overzichten minder ontwikkeld zijn. Het oordeel van de accountant is dan moeilijker te vormen; de kans op een onjuist oordeel is groter. De betrokkenen - die de accountant uiteraard bekend zijn - zullen over de mate van onzekerheid omtrent de juistheid zo nodig moeten worden ingelicht.

\section{Ad d. Mededelingen tijdens de jaarvergadering e.d.}

Hoe perfect ook de organisatie met betrekking tot het op de voet volgen van de bedrijfsontwikkeling moge zijn, het laatste deel daarvan: de wijze waarop in de jaarvergadering mededeling van de uitkomsten wordt gedaan, onttrekt zich aan elke organisatorische controle.

De accountant draagt zeker de verantwoordelijkheid voor een juiste informatie ter zake van de leiding. Indien de leiding deze juiste informatie onjuist in de vergadering weergeeft, kan de accountant hiervoor uiteraard geen verantwoordelijkheid dragen. Men bedenke dat een „onjuiste” weergave niet behoeft te betekenen het noemen van een ander cijfer dan de interne informatie aangeeft; veelal leidt ook het achterwege laten van de vermelding van een bijzondere omstandigheid tot cen verkeerd beeld.

Een bijzonder geval doet zich voor indien de accountant bij het doen van de mondelinge mededeling aanwezig is. Terecht mogen - naar mijn mening - de aanwezigen op grond van het feit dat de accountant zwijgt het vertrouwen hebben dat hij het met de gedane mededelingen eens is. De verantwoordelijkheid van de accountant strekt zich mede uit tot mededelingen met betrekking tot behaalde resultaten en vermogen in zijn bijzijn gedaan door de leiding van de huishouding, waarvan hij zich niet expliciet heef $t$ gedistancieerd.

Ade. Niet in het publiekeverkeergebrachte mededelin$\mathrm{g}$ e $\mathrm{n}$

De casuïstiek is hier zeer uitgebreid. Een algemeen antwoord op de vraag of de accountant voor dergelijke mededelingen verantwoordelijkheid draagt en zo ja tegenover wie, kan worden afgeleid uit de principiële overweging dat ieder die weet dat de accountant fungeert en kennis heeft genomen van de mededeling, het vertrouwen mag hebben dat de accountant van oordeel is dat de mededeling juist is. Voor schriftelijke, niet in het publieke verkeer gebrachte mededelingen zal in het algemeen gelden dat niet kan blijken dat de accountant er kennis van heeft genomen. Van mondelinge mededelingen kan de accountant steeds slechts dan kennisnemen indien zij in zijn bijzijn zijn gedaan.

Tegenover ieder die terecht het vertrouwen heeft dat de accountant van oordeel is dat de mededeling juist is, draagt de accountant verantwoordelijkheid voor die juistheid.

\section{Minder juiste mededelingen in tussentijdse berichten; redres van onjuiste mede- delingen}

In deze paragraaf wordt iets nader ingegaan uitsluitend op de tussentijdse berichten waarbij niet blijkt van het blijven fungeren van de accountant. 
Hiervoren (onder 4, ad a) is gesteld dat tussentijdse berichten die onjuistheden vertonen een verhindering voor de accountant vormen te blijven fungeren. Deze consequentie werd daar afgeleid uit de bij de bedrijfsleiding gegroeide norm van vertrouwen. Het is echter duidelijk dat dezelfde consequentie kan worden afgeleid uit de verantwoordelijkheid van de accountant tegenover het maatschappelijk verkeer indien men bedenkt dat na een onjuiste tussentijdse mededeling opnieuw een jaarrekening wordt gepubliceerd. Ware deze jaarrekening door de accountant gecertificeerd, het maatschappelijk verkeer zou terecht daaraan het vertrouwen ontlenen dat de accountant daarmede eveneens de tussentijdse mededelingen met zijn oordeel heeft gedekt. Daarmede is immers in het publieke verkeer gebracht dat de accountant is blijven fungeren.

Een verdergaande consequentie is nog, dat de hier geschetste situatie van onjuistheden ${ }^{10}$ ) in tussentijdse berichten, gevolgd door een defungeren van de accountant, in het algemeen een verhindering zal vormen voor een andere accountant de opdracht te aanvaarden. In het algemeen, omdat rekening moet worden gehouden met verschillende oordelen van verschillende accountants (hieronder bij de ,,minder juiste mededelingen" besproken) en met de mogelijkheid van redres (eveneens hierna besproken).

Aangezien de strikte onderscheiding: juiste tegenover onjuiste mededelingen lang niet alle gevallen, en wellicht zelfs niet de meerderheid van de gevallen, dekt, dient rekening te worden gehouden met een zekere genuanceerdheid. Ik duid dit aan door te spreken van ,minder juiste” mededelingen. Men kan deze categorie nader afbakenen als: de gevallen waarin twijfel kan bestaan over de vraag of de onvolkomenheid van het bericht al dan niet van belang is voor het uit het bericht af te leiden oordeel. Ondanks een dergelijke twijfel is de accountant uit hoofde van zijn functie verplicht tot een conclusie te komen; het is ook mogelijk dat twee accountants tot verschillende conclusies komen. In feite ligt de problematiek hier niet anders dan indien blijvend verschil van oordeel tussen de bedrijfsleiding en de accountant bestaat omtrent de juistheid van de jaarrekening of enige andere verantwoording waaromtrent het certificaat van de accountant wordt gevraagd, en een uitgenodigde andere accountant een afwijkend oordeel heeft.

Ten aanzien van minder juiste mededelingen dient nog een andere situatie onder ogen te worden gezien. Het is denkbaar dat een minder juiste mededeling ten tijde van het verschijnen van het bericht de accountant tot het oordeel heeft geleid dat van geen onjuistheid ${ }^{10}$ ) sprake was, doch dat een daaropvolgende ontwikkeling heeft duidelijk gemaakt dat het uit het bericht afgeleide oordeel daardoor onjuist is geweest. Een dergelijke ontwikkeling kan op interne, zowel als op externe omstandigheden betrekking hebben. Interne, indien een zich aankondigende tendentie niet of onvoldoende in het tussentijdse bericht is gemeld, terwijl na enige tijd deze tendentie zich scherp of scherper gaat aftekenen. Externe, indien blijkt dat het maatschappelijk verkeer aan de minder juiste mededeling onvoorziene consequenties voor zijn oordeel verbindt. Het zal ongetwijfeld in vele van dergelijke omstandigheden voor de accountant bijzonder moeilijk zijn op zijn eenmaal ingenomen standpunt ter zake van de al dan niet juiste mededeling terug te komen. Niettemin vereist een goede uitoefening van de functie soms een zodanige herziening. De consequenties zijn - zij het op een later tijdstip - dezelfde als in het

10) In de betekenis die daaraan in noot 6 is gehecht. 
geval de accountant reeds dadelijk van oordeel zou zijn geweest dat het tussentijdse bericht onjuistheden bevatte.

Er zijn verschillende redenen waarom de hier gegeven „oplossing” (defungeren bij onjuistheden en verhindering voor een aangezochte opvolger de opdracht over te nemen) alleen, niet bevredigt. In de eerste plaats uit een oogpunt van de bijzondere functie: het is (soms) zeer gemakkelijk te zeggen: Het is fout geweest, ik trek mij terug. De verantwoordelijkheid tegenover de opdrachtgever voor wie men in continuïteit is opgetreden, wordt daarmede geweld aangedaan. In de tweede plaats uit een oogpunt van de algemene functie: indien een onjuistheid in een tussentijds bericht er toe leidt dat de betrokken huishouding het voor enige, of wellicht voor geruime tijd zonder accountantscontrole en accountantsverklaring bij de jaarrekening moet stellen, kan dit noch in het belang van het maatschappelijk verkeer, noch in dat van het accountantsberoep worden geacht. Ten derde zou een wettelijk voorschrift in de geest als voorgestaan door de Commissie Verdam, hier zelfs tot een onwettige situatie kunnen leiden. Ten slotte kan worden geconstateerd dat zo'n ,oplossing", indien zij wordt geëffectueerd, in wezen nicts oplost. De onjuiste mededeling blijft even onjuist; het daarop in het maatschappelijk verkeer gebaseerde oordecl evenzeer; het ontbreken van een accountantsverklaring in het eerstvolgende jaarverslag kan op zijn hoogst tot twijfel bij het maatschappelijk verkeer leiden, doch enige aanwijzing dat er van onjuistheden sprake is of enige indicatie van de aard van de onjuistheid kan op geen enkele wijze in het publicke verkeer worden gebracht.

De consequentie van het defungeren werkt dan ook slechts dan positief, indien zijn niet wordt geëffectueerd. Het is een ultima ratio, die de accountant kan beschermen door afgrenzing van zijn verantwoordelijkheid, doch het maatschappelijk verkeer geen soelaas biedt. Het is mede daarom gewenst, zo niet noodzakelijk, wegen te zoeken die het vermijden van de consequentie mogelijk maken. Niet alleen daarom, doch ook met het oog op de eerder geschetste situatie waarin pas door een opvolgende ontwikkeling de onjuistheid van een eerder gedane mededeling kan blijken. Men houde hierbij in het oog dat ter zake van de berichten waarover in deze paragraaf wordt gesproken, de situatie geheel anders is dan bij de jaarrekening. Dáár een verklaring van de accountant bij een rekening die hij $d u s$ vooraf heeft goedgekeurd; híér geen verklaring van de accountant bij cen bericht waarvan het onzeker is of hij er vooraf van heeft kennisgenomen (ingeval van mondelinge mededelingen kan hij er zelfs vooraf geen kennis van nemen) en, zo ja, of hij het dan wel of niet heeft goedgekeurd.

Het een en ander leidt tot de gedachte dat redres van de onjuiste mededeling mogelijk moet zijn. Gegeven het feit dat de accountant vrijwel nimmer zelfstandig in het openbaar treedt en het - naar mijn subjectieve oordeel - ook ongewenst is dat dit zou geschieden, zal het redres van de bedrijfsleiding dienen te komen. Het hangt uiteraard van het tijdstip, de formulering en de verspreiding van het redres af, of de accountant de consequentie van het defungeren kan vermijden.

Voor de goede orde zij opgemerkt dat hier, noch in de overige paragrafen, is gesproken over het extreme geval waarin de bedrijfsleiding bewust onjuistheden in tussentijdse berichten opneemt, teneinde daarmee een valse voorstelling van zaken te geven. Het lijdt naar mijn oordeel geen twijfel dat het blijven fungeren van de accountant in zodanige omstandigheden de algemene functie zo sterk 
aantast, dat het onaanvaardbaar is. Dit extreme geval doet zich in het Nederlandse maatschappelijk bestel ook zeer inf requent voor.

\section{Conclusies}

1 Het is onjuist indien gezaghebbende beroepsorganen uitspraken doen omtrent de verantwoordelijkheid van de accountant voor mededelingen die niet als zodanig door hem zijn gecertificeerd, zonder daarbij te onderscheiden in welke omstandigheden en tegenover wie die verantwoordelijkheid geldt en in welke omstandigheden en tegenover wie zij niet kan gelden. Dit kan leiden tot een overdreven vertrouwen.

2 Op het feit dat een accountant vorige jaarrekeningen heeft gecertificeerd mag het maatschappelijk verkeer niet het vertrouwen baseren dat de - niet gecertificeerde - mededelingen door het accountantsoordeel worden geschraagd. Het is de plicht van de accountantsstand in het algemeen en van de beroepsorganisaties in het bijzonder het maatschappelijk verkeer hierop te wijzen.

3 Slechts degenen die weten dat de accountant nog in functie is, van de tussentijdse mededeling kennis heeft genomen en in de gelegenheid is van zijn eventueel afwijkend oordeel blijk te geven, kunnen terecht vertrouwen dat de mededeling door het oordeel van de accountant wordt gedekt. Tegenover hen draagt de accountant verantwoordelijkheid. Aangezien de bedoelde wetenschap steeds in ieder geval bij de leiding van de huishouding aanwezig is, draagt de accountant steeds tegenover deze leiding de verantwoordelijkheid. In principe vloeit deze voort uit de functie als controlerend orgaan van de bedrijfsleiding, niet als controlerend orgaan van het maatschappelijk verkeer.

4 Indien na een niet gecertificeerd tussentijds bericht een jaarrekening in het publieke verkeer wordt gebracht voorzien van een goedkeurende accountantsverklaring, kan het maatschappelijk verkeer hierop terecht het vertrouwen baseren dat de mededeling in het tussentijdse bericht door het oordeel van de accountant wordt gedekt. De accountant kan de hieruit voortvloeiende verantwoordelijkheid slechts omgaan door het teruggeven van de opdracht. Deze ultima ratio dient te kunnen worden vermeden door de mogelijkheid van redres open te houden.

5 Indien te zijner tijd, mede op basis van een wettelijke regeling, de norm van vertrouwen ten aanzien van tussentijdse berichten verder groeit, zodat voor de juistheid daarvan mede op het accountantsoordeel wordt gesteund, dienen maatregelen te worden getroffen opdat de wetenschap bedoeld in de aanhef van conclusie 3 publiekelijk bestaat. Dit is mogelijk door certificering van tussentijdse berichten of door publikatievoorschriften in openbare registers.

6 Indien een tussentijds bericht is opgenomen in een stel van bescheiden waarin de naam van de accountant voorkomt, draagt deze tegenover ieder die daarvan kennis kan nemen de verantwoordelijkheid voor de juistheid van het tussentijdse bericht.

7 Het is gewenst te overwegen welke maatregelen kunnen worden getroffen indien door een gecontroleerde ten onrechte de indruk wordt gevestigd dat het onder 6 bedoelde geval zich voordoet.

\section{Samenvatting}

Verantwoordelijkheid van een accountant wordt afgeleid uit het vertrouwen dat 
in zijn verklaringen wordt gesteld. Indien er een overdreven vertrouwen is, beperkt dit niet de verantwoordelijkheid. Wel is dit een aanwijzing dat de accountantsstand maatregelen dient te treffen om het vertrouwen tot een gerechtvaardigd peil terug te brengen.

Het begrip ,verklaring" dient niet te worden beperkt tot expliciete mededelingen. Ook uit het achterwege laten van een mededeling kan onder bepaalde omstandigheden een oordeel van de accountant worden afgeleid.

Het vertrouwen van het publiek dat de accountant die de voorgaande jaarrekening(en) heeft gecertificeerd, ook op het tijdstip van het verstrekken van tussentijdse mededelingen nog fungeert en van oordeel zal zijn dat die mededelingen juist zijn, is een overdreven vertrouwen. De accountant beschikt niet over aanvaardbare middelen van zijn defungeren of zijn afwijzend oordeel kennis te geven.

Slechts zij die - uit hoofde van hun functie of door kennisneming van een schriftelijke mededeling waaruit de medewerking van de accountant blijkt, of aan wie een mededeling in het bijzijn van de accountant is gedaan - weten dat de accountant nog fungeert en dat hij van de mededeling heeft kennisgenomen, kunnen terecht vertrouwen dat de mededeling door het accountant's oordeel wordt gedekt. Slechts tegenover hen kan de accountant verantwoordelijkheid voor de juistheid van de mededeling dragen. Hun zal hij moeten kenbaar maken indien hij van oordeel is dat de mededeling onjuist is.

Het defungeren van de accountant - onvermijdelijk uit een oogpunt van verantwoordelijkheid tegenover de bedrijfsleiding en tegenover het maatschappelijk verkeer bij tussentijdse berichten die tot een onjuist oordeel leiden - geeft wel voor de accountant, doch niet voor het maatschappelijk verkeer een oplossing. De mogelijkheid van redres van een onjuiste mededeling dient te worden opengehouden. 